Editor's Note: These short reviews of a recent paper in the Journal, written exclusively by graduate students or postdoctoral fellows, are intended to mimic the journal clubs that exist in your own departments or institutions. For more information on the format and purpose of the Journal Club, please see http://www.jneurosci.org/misc/ifa_features.shtml.

\title{
$\Delta$ FosB: A Molecular Gate to Motivational Processes within the Nucleus Accumbens?
}

\author{
David Belin ${ }^{1}$ and Aude Rauscent ${ }^{2}$ \\ ${ }^{1}$ Department of Experimental Psychology, University of Cambridge, Cambridge CB2 3EB, United Kingdom, and ${ }^{2}$ Laboratoire de Physiologie et \\ Physiopathologie de la Signalisation Cellulaire, Unité Mixte de Recherche 5543, Université Victor Segalen Bordeaux 2, 33076 Bordeaux Cedex, France \\ Review of Olausson et al. (2006) (http://www.jneurosci.org/cgi/content/full/26/36/9196)
}

The nucleus accumbens (NAc) has long been seen as the interface between limbic and motor systems (Mogenson et al., 1980) on the basis of its convergent glutamatergic inputs from many limbic cortical structures, such as the prefrontal cortex, and its outputs to structures involved in motor control, such as the pallidum. The NAc also receives a major dopaminergic innervation from the ventral tegmental area via the mesolimbic pathway that is intimately involved in rewardrelated processes and addiction. Within the NAc, dopaminergic and glutamatergic inputs might interact to control goaldirected instrumental behavior (response-outcome processes) driven by natural rewards (food, water, sex) or drugs of abuse, and conditioned stimuli associated with them.

Repeated drug exposure induces longlasting cellular and molecular changes within the NAc that are thought to contribute to the protracted compulsive behavior associated with addiction. Among such adaptations, the induction of the transcription factor $\Delta$ FosB within the dynorphin-positive medium spiny neu-

Received Sept. 21, 2006; revised Sept. 28, 2006; accepted Sept. 28, 2006 This work was supported by grants from Région Aquitaine-Centre National de la Recherche Scientifique and the Fyssen Foundation to A.R. and D.B., respectively.

Correspondence should be addressed to David Belin, Department of Experimental Psychology, University of Cambridge, Downing Street, Cambridge CB2 3EB, UK. E-mail: bdb26@cam.ac.uk.

DOI:10.1523/JNEUROSCI.4135-06.2006

Copyright $\odot 2006$ Society for Neuroscience $\quad$ 0270-6474/06/2611809-02\$15.00/0 rons is of major interest. $\Delta$ FosB has been the first long-lasting transcriptional regulator shown to be involved in the plastic processes associated with the transition to addiction. Indeed, it modulates the rewarding and motivational effects of cocaine and is associated with tolerance to the effects of opiates. However, to date, little was known about the role of $\Delta$ FosB in the modulation of behaviors motivated by natural rewards.

In their article recently published in The Journal of Neuroscience, Olausson et al. elegantly address this question by demonstrating that overexpression of $\Delta$ FosB potentiates and increases, respectively, both the acquisition of instrumental conditioning for, and the motivation to obtain, food.

Olausson et al. first analyzed the impact of repeated injections, under conditions known to induce $\Delta \mathrm{FosB}$, of five different drugs: cocaine, nicotine, (+)-3,4-methylenedioxymethamphetamine (MDMA), and amphetamine, on the acquisition of lever pressing for food pellets in food-deprived rats. Except for MDMA, all pretreatments induced behavioral sensitization and all increased both the number of active lever presses emitted by the rats during instrumental conditioning [Olausson et al. (2006), their Fig. 1 (http://www.jneurosci.org/cgi/content/ full/26/36/9196/F1)] and the motivation to obtain food as measured by an increased breaking point on a progressive ratio schedule (PR) [Olausson et al. (2006), Fig. 2B (http://www.jneurosci.org/cgi/content/full/ 26/36/9196/F2)]. Thus, a treatment known to induce $\triangle F o s B$ in the NAc can increase instrumental responding for food. Olausson et al. then attempted to demonstrate a causal relationship between NAc expression of $\Delta \mathrm{FosB}$ and the observed increased motivation for food. For this, they used two models of artificial induction of $\triangle$ FosB in the NAc. They first studied transgenic NSE-tTA-TetOP- $\Delta$ FosB mice, which overexpress the protein only in the dynorphinpositive neurons of the striatal complex when doxycycline (the molecular switch that suppresses TA promoter activity) is removed (Fig. 1A). These mice expressed $\Delta$ FosB not only in the NAc but also in the dorsal striatum, which is more involved in habit learning (Yin et al., 2004) (i.e., automatic stimulus-response processes characterized by insensitivity to reward devaluation). The authors thus induced specific overexpression of $\Delta \mathrm{FosB}$ in the core of the $\mathrm{NAc}$ using viral-mediated gene transfer in rats. In both experiments, artificial expression of $\Delta$ FosB mimicked the potentiating effect of repeated drug exposure on both the acquisition of instrumental responding [Olausson et al. (2006), their Figs. 3 (http: // www. jneurosci.org/cgi/content/full/26/36/9196/F3) and 5 (http://www.jneurosci.org/cgi/content/full/26/36/9196/F5)] and motivation for food [Olausson et al. (2006), their Figs. $4 A$ (http://www.jneurosci.org/cgi/content/ full/26/36/9196/F4) and 7 (http://www. jneurosci.org/cgi/content/full/26/36/9196/ F7)] (Fig. 1B). However, it did not modify the motivation to obtain food under ad libitum conditions, suggesting that the ob- 
served phenotype is revealed only when the animal faces a behavioral challenge, which has been shown to depend on dopaminergic neurons projecting to the NAc (Salamone et al., 1994).

The observed effects were not attributable to increased nonspecific activity, because in all experiments instrumental responding by both rats and mice was directed only toward the active manipulandum. Moreover, it is unlikely that the enhanced instrumental responding observed in both experiments was attributable to $\Delta$ FosB-induced habit learning, because (1) the scores displayed by transgenic mice overexpressing $\Delta$ FosB in $\mathrm{PR}$ were sensitive to satiety-induced reinforcer devaluation, and (2) even when in rats the overexpression of $\Delta$ FosB followed instrumental training, thus preventing any interaction between the artificial overexpression and training, it increased the motivation to obtain food during a subsequent PR.

These results clearly show that overexpression of $\Delta$ FosB in the NAc enhances instrumental responding and increases motivation for food (Fig. $1 B$ ). $\Delta$ FosB is thus suggested to be a general molecular switch involved in the modulation of motivational aspects of goal-directed behavior. It is clear that this demonstration is a key element in the understanding of reward-related processes, which consequently suggests interesting questions for additional investigations.

The results of Olausson et al. were based on induction of $\Delta$ FosB in the NAc by either noncontingent experimenterdelivered drug injections or artificial overexpression, and only addressed goaldirected behavior toward food. The next step would thus be to address the role of $\Delta$ FosB in the context of compulsive drug seeking. Indeed, when addiction develops, compulsive behavior is directed exclusively toward the drug, whereas natural rewards like food are neglected. It would thus be very important to determine, after the development of compulsive drug seeking (Vanderschuren and Everitt, 2005), whether $\Delta$ FosB is induced in the NAc or in more dorsal parts of the striatum, involved in habit-based inflexible behaviors and whether it is associated with enhanced or reduced motivation for natural rewards. A second hypothesis that might be taken into account in future investigations relies on the demonstration that different NAc neuronal subpopulations respond specifically to different rewards during operant behavior (Carelli et al., 2000). Because it seems unlikely that
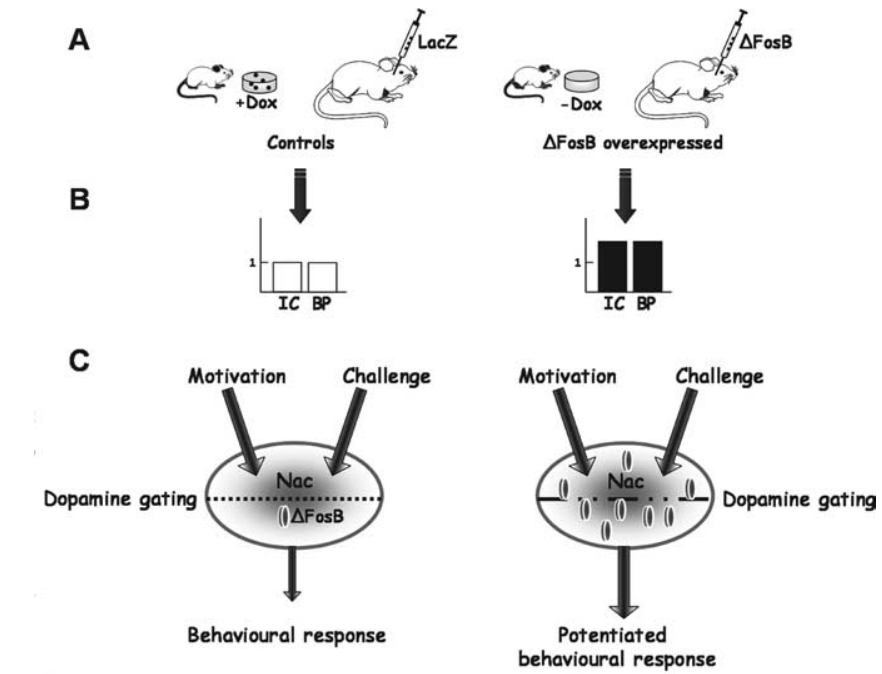

Figure 1. Overexpression of $\Delta \mathrm{FosB}$ in the nucleus accumbens increases instrumental responding for food in mice and rats: new insights for the gating hypothesis of dopamine? A, Experimental model. Control animals (left) were bitransgenic NSE-tTATetOP- $\Delta$ FosB mice given doxycycline (Dox) or rats injected with LacZ-cDNA containing herpes virus. Both did not express $\Delta$ Fos $B$. Right, Bitransgenic NSE-tTA-TetOP- $\Delta$ FosB mice deprived from doxycycline expressed $\Delta$ FosB in the striatal complex, whereas rats injected in the core of the NAc with $\Delta$ FosB -cDNA containing herpes virus expressed $\Delta$ FosB specifically in this structure. $\boldsymbol{B}$, Summary of the results. When challenged to acquire an instrumental conditioning (IC) (i.e., pressing a lever to obtain food) or during a $\mathrm{PR}$, animals overexpressing $\Delta \mathrm{Fos} B$ displayed an increased instrumental responding compared with control animals. BP, Breaking point. $\boldsymbol{C}$, Theoretical perspective. Under normal conditions (left), the behavior displayed by an animal facing a challenge to obtain a reward is controlled both by the contingency between its action and the outcome, and the motivational value of the reward. Within the NAC, dopamine could control a functional window through which the appropriate behavioral response to the motivational cues would be selected. When $\Delta$ FosB is overexpressed (right), this window would be widened, and this would contribute to a stronger behavioral response to the same motivational stimuli.

noncontingent experimenter-delivered injections or artificial overexpression of $\Delta$ FosB can account for this rewardspecific neuronal response, networkspecific expression of $\Delta$ FosB might profitably be investigated. Indeed, if prolonged drug self-administration is associated with specific induction of $\Delta \mathrm{FosB}$ in the NAc subnetwork mediating motivational responses for drugs, an enhanced behavioral response for drugs, and only for drugs, to the detriment of natural rewards like food would be expected. Therefore, based on the present, exciting results, it is now important to use current animal models of compulsive drug seeking, based on chronic self-administration. In this way, we may gain additional insight into the role of $\Delta$ FosB in the development of compulsive drug-seeking behavior to the detriment of the seeking of natural rewards that appear to be relatively devalued in addicts (Diagnostic and Statistical Manual of Mental Disorders IVR).

At a more theoretical level, these results are consistent with the gating hypothesis of dopamine function (Grace, 2000). It can be proposed that, within the NAc, $\Delta$ FosB may widen the functional window of control by dopamine of goaldirected behavioral output in response to presentation of salient stimuli (Fig. 1C). It could thus be argued that, even without higher incentive value, the same stimulus could induce a greater behavioral response when $\Delta$ FosB is artificially overexpressed.

\section{References}

Carelli RM, Ijames SG, Crumling AJ (2000) Evidence that separate neural circuits in the nucleus accumbens encode cocaine versus "natural" (water and food) reward. J Neurosci 20:4255-4266.

Grace AA (2000) Gating of information flow within the limbic system and the pathophysiology of schizophrenia. Brain Res Brain Res Rev 31:330-341.

Mogenson GJ, Jones DL, Yim CY (1980) From motivation to action: functional interface between the limbic system and the motor system. Prog Neurobiol 14:69-97.

Olausson P, Jentsch JD, Tronson N, Neve RL, Nestler EJ, Taylor JR (2006) $\Delta$ FosB in the nucleus accumbens regulates food-reinforced instrumental behavior and motivation. J Neurosci 26:9196-9204.

Salamone JD, Cousins MS, McCullough LD, Carriero DL, Berkowitz RJ (1994) Nucleus accumbens dopamine release increases during instrumental lever pressing for food but not free food consumption. Pharmacol Biochem Behav 49:25-31.

Vanderschuren LJ, Everitt BJ (2005) Behavioral and neural mechanisms of compulsive drug seeking. Eur J Pharmacol 526:77-88.

Yin HH, Knowlton BJ, Balleine BW (2004) Lesions of dorsolateral striatum preserve outcome expectancy but disrupt habit formation in instrumental learning. Eur J Neurosci 19:181-189. 